\title{
Correction to: A prospective randomized trial comparing corifollitropin-a late-start (day 4) versus standard administration (day 2 ) in expected poor, normal, and high responders undergoing controlled ovarian stimulation for IVF
}

\author{
Alberto Revelli ${ }^{1}$. Gianluca Gennarelli ${ }^{1}$ - Marta Sestero ${ }^{1} \cdot$ Stefano Canosa ${ }^{1} \cdot$ Andrea Carosso $^{1} \cdot$ Francesca Salvagno $^{1}$. \\ Giulia Pittatore $^{1} \cdot$ Claudia Filippini $^{2} \cdot$ Chiara Benedetto $^{1}$ \\ Published online: 22 May 2020 \\ (C) Springer Science+Business Media, LLC, part of Springer Nature 2020
}

Correction to: Journal of Assisted Reproduction and Genetics https://doi.org/10.1007/s10815-020-01742-5

The original article unfortunately has a missing acknowledgement.

The study was supported by the economical contribution of MSD Italy s.r.l. The opinions reported in the article belong to the authors and do not necessarily coincide with those of MSD Italy s.r.l.

The online version of the original article can be found at https://doi.org/ $10.1007 /$ s10815-020-01742-5

\section{Alberto Revelli}

alberto.revelli@unito.it

1 Gynecology and Obstetrics 1, Physiopathology of Reproduction and IVF Unit, Department of Surgical Sciences, S. Anna Hospital,

University of Torino, Via Ventimiglia 3, 10126 Turin, Italy

2 Clinical Statistics, Department of Surgical Sciences, University of Torino, Corso Bramante 88, Turin, Italy 